\title{
Stability Analysis of Tailings Dam Based on Coupling Seepage and Stress
}

\author{
Lina ZHANG \\ Civil and Architectural Engineering Department \\ East China University of Technology \\ Nanchang, Jiangxi, China \\ e-mail: zlnecit@163.com
}

\author{
Fengchen LI \\ Civil and Architectural Engineering Department \\ East China University of Technology \\ Nanchang, Jiangxi, China \\ e-mail: fcli_1980@163.com
}

\author{
Cide PENG \\ Civil and Architectural Engineering Department \\ East China University of Technology \\ Nanchang, Jiangxi, China \\ e-mail: fchli@ecit.cn
}

\begin{abstract}
With the high development of the mine enterprise in China, the scale of the tailings' design is becoming bigger and bigger, the safety of the tailings becomes more and more important. As one of the most important parts, the tailings dams turn to be 'disaster zone' with frequent accidents. Therefore, Tailing Dam's stabilities is particularly important. This paper based on the theory of Seepage coupling and Stability analysis, taking the powerful non-linearly finite element software ABAQUS to make simulation analysis of tailing dam, and comparative analysis with the results of classical ultimate balance method, the concluding part raises the prospect of methods for stability analysis of tailing dam. Considering un-saturation coupling between seepage and stress, the article builds two-dimensional tailings dam model, then simulates or computes it applying ABAQUS. Strain-stress, displacement, plasticity and saturation line nephogram could be acquired by powerful graphical post-processing module. The safety factor of the dam could be obtained by strength reduction method.
\end{abstract}

Keywords-tailings dam; coupling seepage and stress; limit equilibrium method; ABAQUS; safety factor

\section{INTRODUCTION}

Tailing dam [1] is the important part of tailing pond facility, which hidden huge security danger and prone to cause accident. Besides, the normal operation of tailing pond depends on the stability of tailing dam. Many serious mine accidents are sparked off by the failure of tailing dam project in the world, so the tailing dam safety problem has become the most important component of the tailing safety work [2].

So far the tailing pond project is usually simplified tailing dam as general slope or dam, using classical ultimate balance method (including slip circle method, Janbu method, Bishop Method and so on). Though the principle of classical ultimate balance method is quite simple, obtained results lack of reliable and reflect insufficient information.

In the recent years, with the development of computer technology, Numerical Simulation Analysis is widely used in this field, many research institutions at home and abroad have developed numerical simulation software (such as ABQUS), which considering more factors (such as seepage coupling, complex boundary). Through numerical simulation software, the stability coefficient of the dam and other information can be obtained, as a guide to the design and construction of the tailing dam project.

\section{ANALYSIS PRINCIPLES}

\section{A. Seepage Coupling Theory}

The relationship between seepage field and stress field is mutual influence and role [3]. On the one hand, the change of seepage force will cause the change of seepage volume or hydrostatic pressure, which makes the engineering structure or external load effecting geology body and stress field to change; On the other hand, the change of stress field causes structures to occur deformation, which change its internal porosity and permeability coefficient, thus change the flow field. Under the seepage field and stress field interaction, ultimately, it makes the double field to reach a stable equilibrium, which form a stable seepage field under steady stress and stress field under the influence of seepage field of influence, respectively.

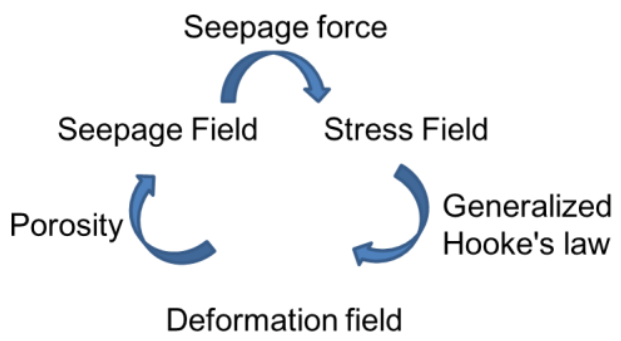

Figure 1. Coupling seepage and stress sketch

\section{B. Limit Equilibrium Analysis}

Limit equilibrium analysis is a balanced analysis by unstable soil static, according to Mohr Coulomb criterion body slope stability analysis [4]. 


\section{1) Sweden sliding method:}

Swedish sliding law is a slope stability method based on Sweden circular slip instance raised by Fellenius, which considering the sliding surface is a continuous circular surface and the whole sliding earth is a large rigid body [5]. The landslide is divided into several strips of soil, and ignores the force of their own strain and columns between the individual slices. Therefore, Sweden sliding method is a simplified slice method, which cannot meet all the static equilibrium conditions, and the safety factor is calculated to give more stringent than other methods to be small. As shown in Figure2, the law generally based on the analysis of total stress, and safety factor is defined as the entire anti-slide surface sliding surface slip torque and can provide all the slip ratio of the torque. The equation is shown as (1).

$$
F_{s}=\frac{\sum\left(c_{i} l_{i}+G_{i} \cos \alpha_{i} \operatorname{tg} \varphi_{i}\right)}{\sum G_{i} \sin \alpha_{i}}
$$

Where $F_{s}$ is the safety factor or stability factor $c_{i}$ is soil cohesion, $\varphi_{i}$ internal friction angle of soil, $l_{i}$ is the length of slide arc, $G_{i}$ is the weight of soil.

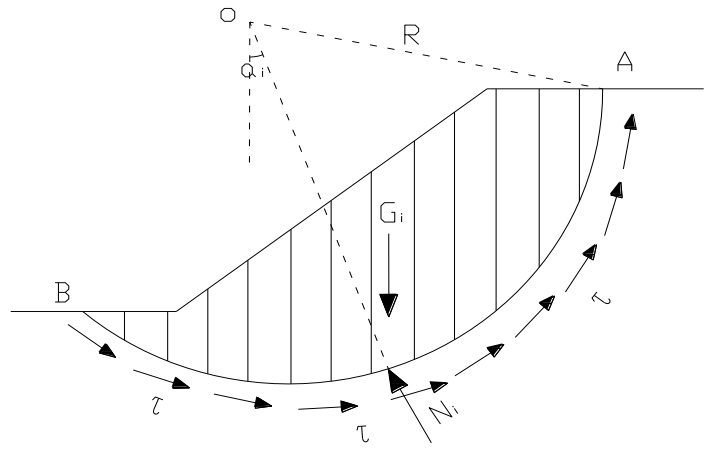

Figure 2. Swedish slice method sketch

\section{2) Bishop method:}

Bishop slice method assumes sliding surface as an arc, which regards landslide as a rigid body, considering horizontal lateral force among slices, and assumes that the coefficient of stability against sliding bar at the bottom of each soil sliding surface are the same [6]. Through analysis the force balances, stability coefficient expression as shown in Equation (2).

$$
\begin{gathered}
F_{s}=\frac{\sum \frac{1}{m_{i}}\left(c_{i} l_{i}+G_{i} \operatorname{tg} \varphi_{i}\right)}{\sum G_{i} \sin \alpha_{i}} \\
m_{i}=\cos \alpha_{i}+\frac{\operatorname{tg} \varphi_{i}}{F_{s}} \sin \alpha_{i}
\end{gathered}
$$

\section{3) Janbu method:}

Janbu method assumed arbitrarily shaped slip surface along the weak layer of the interface, and the slider is divided into several strips of soil [7]. After any sliding surface is divided into $\mathrm{n}$ soil column, assumptions point of location is always the height of the soil column at 3 points. Force balance analysis of each soil column is performed, and ultimately the slope stability factor is obtained.

\section{CASe Analyses}

\section{A. Project Profile}

According to the construction time and function, the tailing dam is divided into initial dam and post dam. The dam foundation is a medium/slightly weathered Phyllite (water insulation course), which would be cleared before construction. The integrity of rock mass is better, what's more, in its natural state, it have good stability. Both sides of dam are lithological slope, and there are no signs of collapse and slip, and good stability in its natural state.

The dam height is 208 meters, the water level in the upstream reservoir is about 218 meters, and the overflow point of downstream water level is about 82 meters, so it would produce seepage force. Under the action of steady seepage, the stability of downstream face of dam (free surface) is slightly worsened, so it needs to make stability analysis of downstream dam slope.

From top to down, the dam is composed of four elements:

(1) Fine sand

(2) Tail silty sand, according to the simplified homogeneous sand layer to calculation, the relationship between permeability coefficient and void ratio is shown in Table I , the relationship between pore pressure and degree of saturation is shown in Table II .

TABLE I. THE PERMEABILITY COEFFICIENT CORRESPONDING WITH DIFFERENT PRESSURE AND POROSITY RATIO

\begin{tabular}{cccccccc}
\hline Pressure (Kpa) & 0 & 50 & 100 & 200 & 500 & 1000 & 2000 \\
\hline Void Ratio & 0.96 & 0.93 & 0.81 & 0.79 & 0.74 & 0.68 & 0.60 \\
\hline $\begin{array}{c}\text { Permeability } \\
\text { Coefficient } \\
\left(\mathbf{1 0}^{-6} \mathbf{m} / \mathbf{s}\right)\end{array}$ & 4.39 & 3.65 & 2.20 & 1.71 & 1.59 & 1.38 & 1.00 \\
\hline
\end{tabular}

TABLE II. The RELATIONSHIP BETWEEN Pore PRESSURE AND SATURATION

\begin{tabular}{ccccccc}
\hline Pore Pressure (KPa) & -200 & -150 & -100 & -50 & -20 & 0 \\
\hline Saturation & 0.0215 & 0.0464 & 0.10 & 0.417 & 0.99 & 1.00 \\
\hline
\end{tabular}

(3) Clay stone (initial dam), the sliding surface will not pass through this layer by preliminary judgment, and the cohesion and friction angle should be amplified.

(4) The rock mass of moderately weathered phyllite has a good integrity, and it can be regarded as rigid body.

\section{B. The Stability Analysis of Beijing Lizheng Software}

Without considering the effect of earthquake, based on the Swedish slice method, Janbu method and Bishop method, by using slip circle method to calculate the safety factor of this tailing dam in the condition of steady seepage, and this 
method comes from Specification for Design of Rolled Earth Rock Dam (SL274-2001), adopting specify center and search range or automatically search the most dangerous slip surface method to determine the sliding surface. Calculation diagram is shown in Figure3. Safety factor summary is shown in Table III.

TABLE III. SAFETY FACTOR SUMMARY

\begin{tabular}{cccc}
\hline \multirow{2}{*}{$\begin{array}{c}\text { Steady Seepage } \\
\text { Phase }\end{array}$} & \multicolumn{3}{c}{ Safety Factor } \\
\cline { 2 - 4 } & $\begin{array}{c}\text { Swedish slice } \\
\text { method }\end{array}$ & $\begin{array}{c}\text { Bishop } \\
\text { method }\end{array}$ & $\begin{array}{c}\text { Janbu } \\
\text { method }\end{array}$ \\
\hline Non-earthquake & 1.860 & 1.887 & 1.871 \\
\hline
\end{tabular}

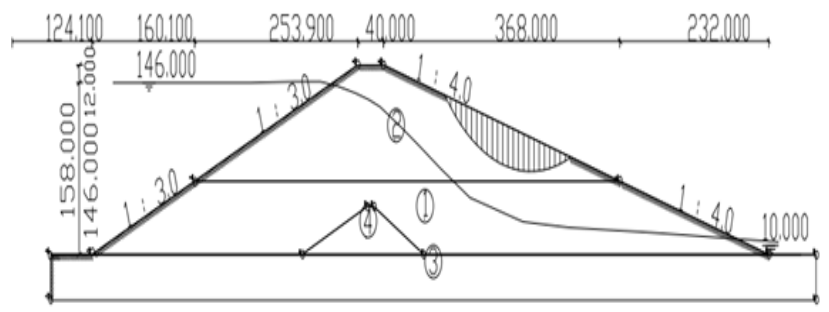

Figure 3. Calculation diagram

\section{The Analysis of ABAQUS Seepage and Stability}

At present, the dam is in steady seepage phase, according the above project profile to establish model, on the basis of formula (3) to setup pore pressure boundary of upstream dam slope, the bottom is 2.5 meters thick sand and gravel drainage layer which permeability coefficient is $1.0 \times 10-5 \mathrm{~m} / \mathrm{s}$, the dam foundation is impervious boundary, the type of mesh element is CPE4P (four node plane strain pressure cell), according to the seepage and stress coupling principle, this can establish two dimensional model of unsaturated seepage flow by using ABAQUS.

$$
P_{h}=146 \times\left(146-Y_{h}\right)
$$

Where $P_{h}$ is the slope water pressure corresponding to the water level $h, \mathrm{kPa}, Y_{h}$ is the absolute elevation corresponding to the water level $h, \mathrm{~m}$. When the $Y_{h}$ is greater than 146 , the water pressure is 146 , which indicates that the water level above the water level line is zero.

By applying ABAQUS, it can be obtained contour lines of pore pressure (shown in Figure 4) and saturation contour (shown in Figure 5).

According to the contour lines of pore pressure, we can obtain the following conclusions, the dam include saturated seepage and unsaturated seepage, and the dam is nonsaturated region, which exist negative pressure in its top right corner, the others is saturated region. The reservoir water is from upstream to downstream and from saturated region to unsaturated region. From the saturation contour, the red line is saturation line, and the below saturation is one hundred percent, and over this line, the saturation is gradually decrease, corresponding negative pore pressure is increased gradually, that is to say, the matrix suction is gradually increased. The saturation line falls in a curve, because of the permeability of this initial dam is poor, the curve decreased significantly when it go through the initial dam, and because of the high permeability cushion, the curve's slope gradient. The downstream overflow point is over the dam toe about 15 meters or so, this result is accordance with the actual case.

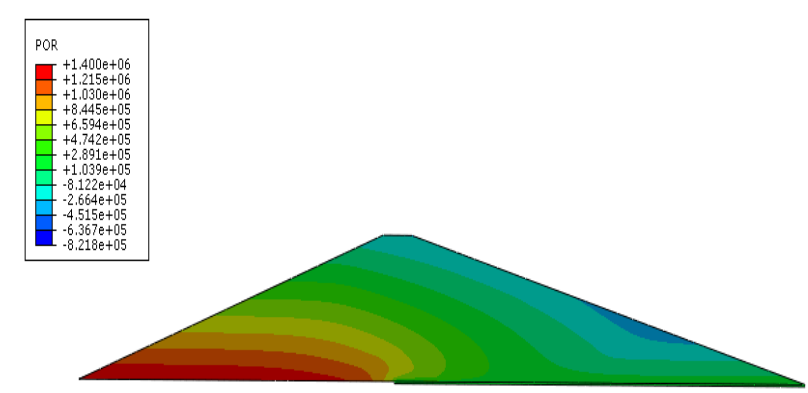

Figure 4. Contour plot of pore pressure

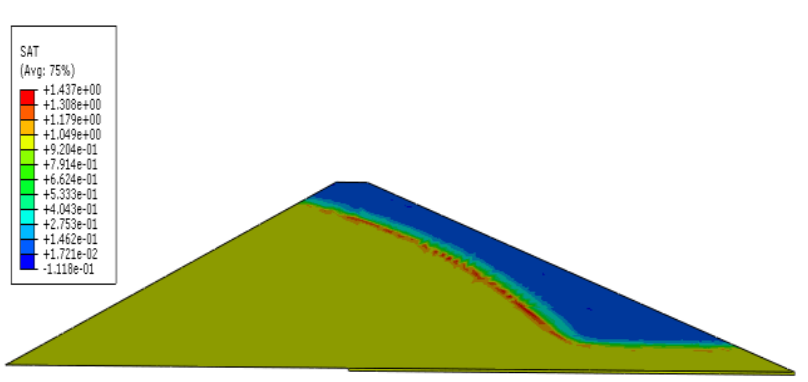

Figure 5. Saturation contour plot

According to the project data, adopting the ABAQUS to establish two dimensional slope analysis models, on the basis of the plastic zone development and the strain filed, and applying strength reduction principle, it can obtain the stability factor of the tailing dam.

Transformed field variable FV1, it can get the equivalent plastic cloud image of the dam in the condition of the different reduction factor. When the reduction factor is 1.550 and $\mathrm{t}=0.7000$, it would found more obvious through area, which is shown in the Figure 6; when the reduction factor is 1.634 and $\mathrm{t}=0.7563$, the plastic cloud image is shown in Figure 7; when the reduction factor is 1.641 and $t=0.7609$, the plastic image is shown in Figure8. When the reduction factor is 1.641, the displacement contour is shown in Figure 9.

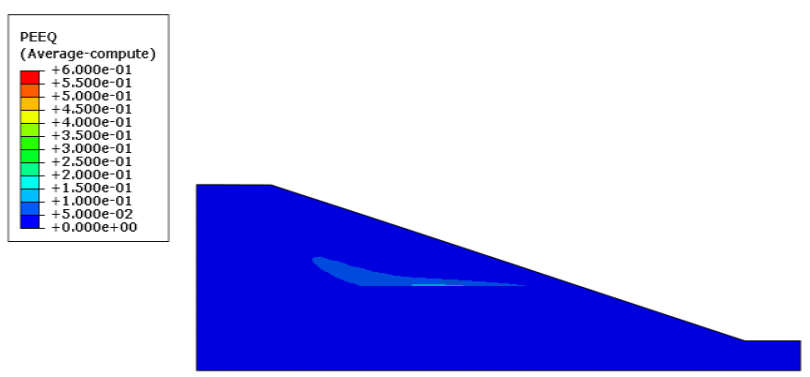

Figure 6. The plastic image $(\mathrm{FV} 1=1.550, \mathrm{t}=0.7000)$ 

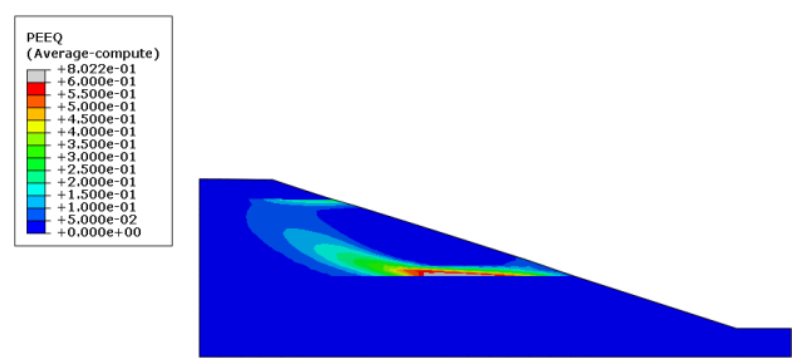

Figure 7. The plastic image $(\mathrm{FV} 1=1.634, \mathrm{t}=0.7563)$
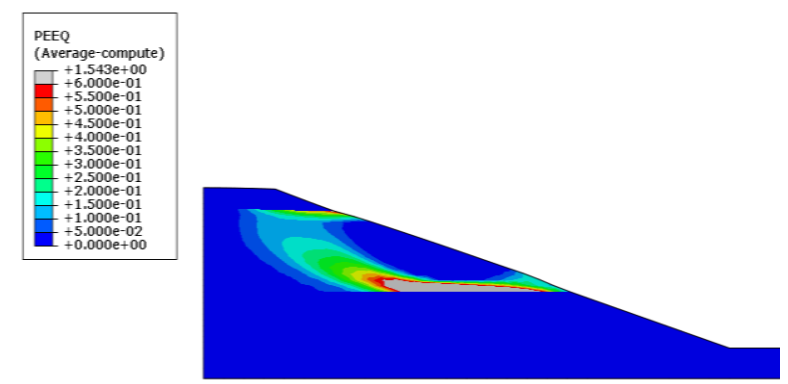

Figure 8 . The plastic image $(\mathrm{FV} 1=1.641, \mathrm{t}=0.7690)$
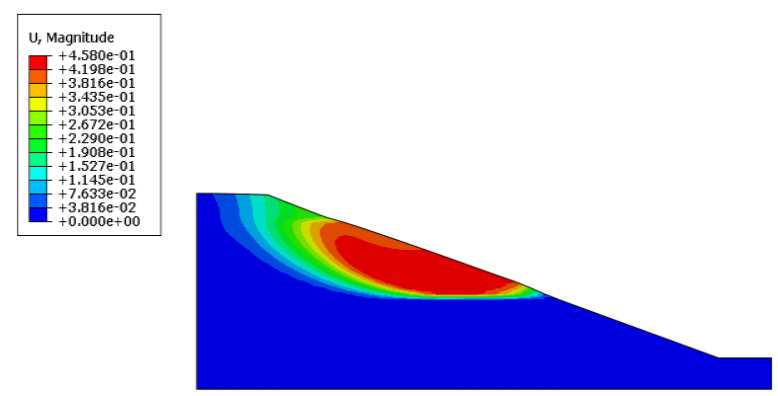

Figure 9. Displacement contour image $(\mathrm{FV} 1=1.641)$

From the above image, when the reduction factor is 1.641 and the time is 0.7609 , the dam will produce the through plastic zone in the upper right, and the zone have larger displacement, and the trend of circular sliding surface will coming soon, so the safety factor of this tailing dam is 1.641.

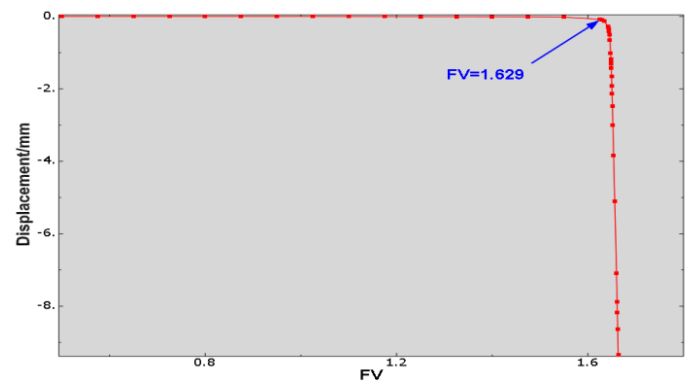

Figure 10. The relationship between $\mathrm{U} 1$ and FV1

Establishing the vertex node point set, and it would take the turning point of horizontal displacement of the point as the evaluation criterion, the relationship between horizontal shift (U1) and reduction factor (FV1) is shown in the below figure, from the Figure10, we can get the safety factor is 1.629 .

\section{CONCLUSIONS AND PROSPECT}

From the analysis of Beijing LiZheng slope software and ABAQUS software, the stability factor of tailing dam all meet the following two standards, the one is that the minimum safety factor of stability against sliding of the two stage tailing dam is 1.250 according to the Sweden arc sliding calculation (the standard is come from Technical Specification for Safety of Tailing Pond) (AQ2006-2005); the another is that the minimum safety factor of the first grade slope engineering is 1.300 which is come from Specification for Design of Tailing Facilities in Mineral Processing Plant. The stability factor which is consider seepage coupling effect will much safer, what's more, applying the strength reduction method and integrating the plastic zone and displacement contour, the stability factor have more reliability.

Using the ABAQUS software to simulate the tailing dam, it would found the shape and position of saturation line, the saturation line is gradually decrease from upstream slope to downstream face of dam, when it go through the initial dam, the line dramatic decline, The downstream overflow point is over the dam toe about 15 meters or so, under this line is saturated flow, while over this line is unsaturated region (negative pressure).

From the above we can know, the ABAQUS have an obvious advantage over the stability analysis of tailing dam, the simulation results and the actual conditions are identical with each other, it can get abundant amount of information, according to the monitoring data, it can dynamic gain the safety condition of tailing dam, it is worth to use and promote in the analysis and evaluation of tailing dam project in the future. However, when use this method, it need more parameters, furthermore, it is difficult to choose the constitutive and boundary, so it need more theoretical research of scholars to make sure in the future.

\section{ACKNOWLEDGEMENT}

This research was supported by Natural Science Foundation of Jiangxi Province (20141BDH80027, 20133BBE50032, 20141BBE50022 and KJLD13052), Science and technology planning project of Jiangxi Provincial Education Department (GJJ14496), China.

\section{REFERENCES}

[1] Z.G.Teng, Analysis and Evaluation on Seismic Stability of Tailing Dam. Hebei Metallurgy, 12(2001).

[2] H.D. Xu, Statistical Analysis of Mine Tailing Dam Accident. Industrial Architecture, 24(2001).

[3] D. G. Frelund, J.Krahn, Comparison of slope stability methods of analysis.Canadian Geotechnical Journal,14(1977).

[4] D.Y. Zhu, Z.F. Li, M.S.Huang. Modifications to three well-known methods of slope stability analysis. Chinese Journal of Rock Mechanics and Engineering, 2(2005).

[5] X.P. Chen, P.Y. Xi, Z.S. Liang, et al. Coupling analysis of heterogeneous earth dam stability of seepage field and stress field. Rock and Soil Mechanics, 25(2004). 
[6] Z.H. Dai, P.SH. Shen, Numerical solution of simplified Bishop method for stability analysis of soil slopes. Rock and Soil Mechanics, 6(2002).
[7] G.Q. Chen, R.Q. Huang, et al. Stability analysis of slope based on dynamic and whole strength reduction methods. Chinese Journal of Rock Mechanics and Engineering, 33(2014). 